\title{
More than CAM and clathrin
}

Cells and tissues are under scrutiny for our cell biology feature. This weeks episode has five new protein kinases, mammalian expression vectors, cell death detection ELISA and proliferating human mesangial cells.

KAYIMA Biomedical has a new product line for free-radical research - carazostatin, pyrrolostatin and NCO-700 should have applications in the research of oxidative damage to biological tissues by freeradicals (Reader Service No. 100). Carazostatin and pyrrolostatin are strong inhibitors of lipid peroxidation induced by free-radicals. Carazostatin shows ex vivo inhibition of lipid peroxidation in mouse plasma and pyrrolostatin shows protective antihypoxic activity in mice. NCO-700 is a thiol protease inhibitor that inhibits oxidant production by fMLP-stimulated PMNs and scavenges reactive oxygen.

Clonetics has released the RenalPackMS a cell system containing cryopreserved or proliferating normal human mesangial cells, optimized mesangial cell growth medium and subculture reagents for the propagation and subculture of the cells in vitro (Reader Service No. 101). The system can be used for immunohistochemical and biochemical studies, the study of filtration residues, peptide cytokines and growth factors, inflammatory response to glomerular injury and mesangial cell proliferation and differentiation.

The Bio-Rad D Gene system is designed for simple and efficient mutation detection (Reader Service No. 102). This is a denaturing gradient gel electrophoresis (DGGE) technique designed to identify single base mutations. The manufacture claims that it can provide up to 99 per cent efficiency. The system utilizes a vertical electrophoresis cell that separate wild-type and mutant fragments.

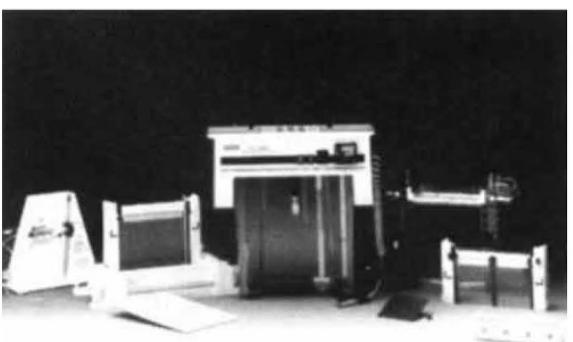

D Gene - mutation detection system.

The process uses a polyacrylamide gel with a denaturing gradient perpendicular to the electric field at a controlled temperature. There are two gel sizes available, a model 475 gradient delivery system, new MacMelt software (for predicting melt patterns), a reagent control kit and a reagent electrophoresis kit.
For the identification of proliferation-associated antigens, Coulter has released Clone p105 and Clone p120 (Reader Service No. 103). These products are intended to detect proliferation antigens that are upregulated during cell proliferation including oncoproteins and nuclear-associated antigens. Proliferative /activity may have an important prognostic significance in several types of cancer, such as non-Hodgkin's lymphoma, neuroblastoma and cancers of the breast, colon, lung, ovary and bladder.

\section{Protein products}

New England Biolabs has expanded its line of protein tools with the introduction of five new protein kinases: casein kinase II, cyclic AMP-dependent protein kinase, glycogen synthase kinase 3 and p34 $4^{\text {cdc } 2 / ~ c y c l i n ~ B ~(R e a d e r ~ S e r v i c e ~ N o . ~}$ 104). These proteins are expressed from recombinant sources, and are purified close to homogeneity and tested for contaminating activity. Related new products include protein phosphotase 1 and its specific inhibitor, I-2.

Among the latest products to be introduced to the Santa Cruz Biotechnology range of signal transduction reagents are members of the Id family of helixloop-helix proteins (Reader Service No. 105). These proteins appear to regulate negatively the DNA binding of bHLH proteins; expression of each of the Id proteins is strongly dependent on growth factor activation. The new proteins are affinity-purified rabbit polyclonal Id 1 (C-20), Id 2 (C-20), Id3 (C-20) and Id4 (L-20). Also offered are new members of the Stat family (signal transducers and activators of transcription) - Stat4 (L-18) and Stat 4 (C-20), which has been suggested to form homodimers as well as heterodimers with the other members of the Stat family.

Oxford Glycosystems now offers phosphotidyl inositol specific phospholipase $C$ (PI-PLC) as a recombinant enzyme isolated from Bacillus subtilis transfected with the PI-PLC gene from Bacillus thuringiensis (Reader Service No. 106). This recombinant enzyme can be produced in bulk quantities and is intended for detection of certain GPI membrane anchors, structure/function studies, pharmaceutical research and therapeutic and vaccine development. The product is supplied in a neutral buffer and is protease free. A number of free pack sizes are available.

\section{Gene expression}

Invitrogen has introduced $\mathrm{pZeoSV}$, the newest member in a line of mammalian expression vectors (Reader Service No. 107). This vector carries the Zeocin resistance gene for selection in both Escherichia coli and mammalian cell lines. By having only one selectable marker, the overall vector size of $\mathrm{pZeoSV}$ is only 3.45 $\mathrm{kb}$, allowing more efficient ligation, transformation and transfection. pZeoSV contains the strong promotor enhancer from the early region of SV40 and is said to allow high-level expression of the desired

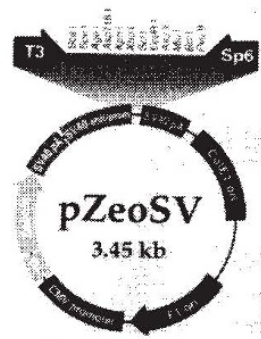

Invitrogen. gene in a variety of mammalian cell lines. The vector also carries a mult-iple cloning site for simplified cloning, the SV40 polyadenylation signal for efficient transcription and an $\mathrm{f} 1$ origin of replication for rescue of single-stranded DNA.

New antisense technologies are designed to permit control of cellular behaviour by manipulation of the expression of specific genes (Reader Service No. 108). TCS Biologicals has now introduced a stable antisense oligonucleotide preparation called Antisense retinoblastoma ( $\mathrm{Rb}$ ) which is directed against the retinoblastoma gene. Expression of the $\mathrm{Rb}$ gene product is a key control element which inhibits eukaryotic cells from entering mitosis. The product can simply be added to the medium to down regulate $\mathrm{Rb}$ gene expression and manufacturer states that the cell proliferation is then stimulated by three to five times. The effects of the antisense nucleotide is said to be reversible and cells revert to their normal doubling time when it is removed. It can be used to promote expansion of primary cultures and 'difficult' cell types including embryonic stem cells.

\section{Cell cycle research}

Promega's line of products for cell cycle research has the tools necessary to investigate cell-cycle control or identify potential anti-mitotic and anti-cancer drugs (Reader Service No. 109). The new product line includes pp34 ${ }^{\mathrm{cdc} 2}$ kinase (eukaryotic cellcycle study), olomoucine (pp34 cdc $2 /$ cyclin B complex inhibitor), cdc2 protein kinase peptide substrate (a synthetic peptide, specific for in vitro phosphorylation sites of histone $\mathrm{H1}$ ) and Anti-pp34 ${ }^{\mathrm{cdc} 2}$ kinase N-terminus (a polyclonal antibody for the active dephos- 
phorylated form of the protein). Also offered is $\mathrm{p} 9^{\mathrm{CksHs} 2}$ agarose that binds cell cycle-dependent protein kinases such as $\mathrm{pp} 34^{\mathrm{cdc} 2}$ kinase, and to affinity purify this protein from human tissue and yeast extracts.

Boehringer Mannheim's new cell death detection ELISA kit is designed for determination of apoptosis — physiologically determined or 'programmed' cell death (Reader Service No. 110). The kit measures the mononucleosomes and oligonucleosomes released into the cytoplasm of cell populations during naturally occurring or experimentally generated apoptosis. Results are said to be obtained in 5-6 h, and

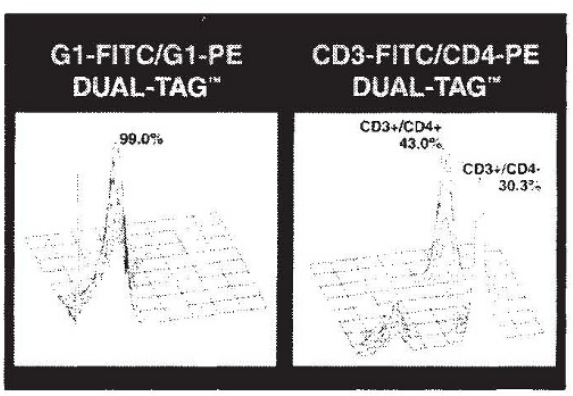

Dual-Tag cell death detection ELISA kit.

the assay does not generate radioactive waste. The kit's sandwich ELISA detects only the histone-associated DNA (nucleosomes, for example) that accompanies apoptosis, not free DNA.

\section{Imaging and assays}

Perseptive Biosystems has developed CytoFluor II for quantitative fluorescent assays (Reader Service No. 111). This instrument can help investigate tissue interactions, including inflammation and tumour formation, by measuring cell adhesion. The manufacturer states that this is done without altering the interaction between CAMs, their receptors, blocking agents, or analogues. In this assay, the fluorescent signal is emitted from cells that have had the volume of the cytosol labelled. Fluorescently labelled cells are added to a 96-well plate coated with monolayers of unlabelled cells such as endothelial or epithelial cells, or extracellular matrix proteins, known to have CAM-like properties. Labelled cells are allowed to adhere and unbound cells are washed away. The fluorescence is measured to determine the number of remaining adherent cells.

Life Science Resources has announced InSitu, an image acquisition and analysis system for molecular and cellular biology laboratories using immunocytochemistry, autoradiography and in situ hybridization (Reader Service No. 112). This system is designed for optical detection technologies capable of reporting quantity and localiza- tion of proteins, antigens, surface receptors and genetic material. It provides quantitative densitometry on fixed cells and tissues, slices, sections and gels. InSitu is suitable for the detection of radioisotopic markers detected by autoradiography as well as light emitting optical reporters coupled to fluorescent, bio- or chemilumine-scent molecular probes. A variety of imaging detector resolutions can be utilized and true colour, 24-bit image acquisition is also offered.

Sigma Immunochemicals has introduced seven new Dual-Tag doublelabelled monoclonal anitbodies to human leukocyte markers for flow cytometry (Reader Service No. 113). The CD Dual-Tag reagents available are human CD3-FITC/CD4-PE, human CD3FITC/ CD8-PE, human CD3-FITC/CD19$\mathrm{PE}$, human $\mathrm{CD} 3-\mathrm{FITC} / \mathrm{CD} 57-\mathrm{PE}$, human CD4-FITC/ CD8-PE, human CD5-FITC/ CD19-PE and human CD45-FITC/CD14$\mathrm{PE}$. The mixed reagents of FITC/PE labelled $\mathrm{CD}$ antibodies provide fluorescent labelling of cell-surface antigens and permit subsets of leukocyte populations to be analysed and sorted. Dual-Tag reagents are designed for characterization of subtypes of T-cell leukaemias and lymphomas; HIV infections, AIDS, and other associated diseases; identification and enumeration of helper/ inducer, helper/suppressor $\mathrm{T}$-cell subclasses and transplant studies.

\section{Cell culture and refinement}

Specialized Culture Technologies has introduced the POC-Culture chamber - - it is designed to allow the culture of many cell types under stationary or continuous perfusion conditions on glass or permeable, hydrophilic or hydrophobic Teflon foil growth surfaces (Reader Service No. 114). In addition, the chamber can be placed in an incubator or directly on a heated microscope stage. The chamber has the same dimensions as a Terasaki plate and an observation area of about $6.6 \mathrm{~cm}^{2}$. It has been designed to accommodate the new high-resolution oil-immersion objective, so that the refractive index of the growth surface does not present a problem.

The Harvest Mouse bioreactor from Serotec is designed for monoclonal antibody production, making affordable, hollow-fibre technology readily available (Reader Service No. 115). This reactor is said to require only a basic level of experience in tissue culture techniques for effective operation. The process is designed to be simple, self-contained and to run in a standard $\mathrm{CO}_{2}$ incubator. The bioreactor can be autoclaved.

These notes are compiled by Brendan Horton from information provided by the manufacturers. For more details, fill in the reader service card bound inside the journal.
ADVERTISEMENTS

\section{Custom PEPTIDE Synthesis}

in sets of

$95+1$ control peptide

for screening of B and T-cell epitopes, receptor binding studies etc.

Less than $\$ 70 / p e p t i d e !$

(up to 18-mer, 2 - $5 \mathrm{mg}$ )

\section{A.F.S. Germany}

Fax 49 - 7071 - 73141

Syntenic LabTracker is the first of several software packages for molecular biologists to be released by Syntenic Limited over the next year. Syntenic LabTracker runs under Windows for the PC and consists of populated databases including restriction enzymes, methylases, modification enzymes and bacterial strains. Syntenic LabTracker therefore provides a focal point to which information can be constantly added to and taken from, allowing information and ideas to be readily shared among the different members of a lab. A 'Commercial Sources' database allows companies which sell the product(s) of interest to be easily identified. Syntenic LabTracker will be available from Syntenic Limited during April 1995. Price $£ 100+$ VAT. For more information or if your company would like to be included in Syntenic LabTracker please contact us directly without delay. Syntenic Limited, Suite 2, Dolphin House, Sutton Harbour, Plymouth, PL4 ODW, UK.

Tel/Fax: 01752256473 (UK)

+441752 256473 (Rest of world)

email: syntenic@trump.demon.co.uk

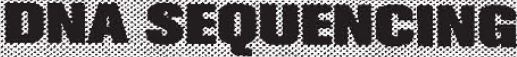

Using an $\mathrm{ABI} 373$

Automated Sequencing System

f45 per run

$\begin{array}{ll}\text { - PCR products } & \text { - single stranded DNA } \\ \text { - M13 inserts } & \text { - double stranded DNA }\end{array}$

$\begin{array}{ll}\text { - M13 inserts } & - \text { double stranded DNA } \\ \text { - plasmid inserts } & -300-400 \text { bases of seque }\end{array}$

Please contact us for moro information

Molecular Medicine Unit King's College School of Medicine \& Dentistry
Tel: $071-3463126$ Fax: 071-733 3877

\section{LUPOSOMES}

REPRODUCIBLE - HOMOGENEOUS EXTREMELY RAPID

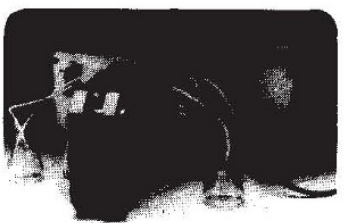

Our new LIPOSOMAT guarantees rapid $(5 \mathrm{ml}$ within 60 minutes) preparation of uniformly sized unilamellar liposomes. Liposome size is selectable between 25 and ca. $600 \mathrm{~nm}$ diameter. Sample volume is normally $5-10 \mathrm{ml}$ or up to $200 \mathrm{ml}$ if used in combination with an additional instrument. Lipid concentration can be up to $300 \mathrm{mg} / \mathrm{ml}$.

P.O. Box 650126, D-81215 Munich For USA call 1-800 Liposome 